\title{
A MORTE DE AMY WINEHOUSE COMO ACONTECIMENTO NO FANTÁSTICO E NO JORNAL NACIONAL
}

LUIZ FERNANDO GREINER BARP UNIVERSIDADE FEDERAL DE SANTA MARIA CHAPECÓ, SANTA CATARINA, BRASIL E-MAIL: BARP.LF@GMAIL.COM. 


\section{A MORTE DE AMY WINEHOUSE COMO ACONTECIMENTO NO FAN- TÁSTICO E NO JORNAL NACIONAL ${ }^{17}$}

Resumo: Analisamos neste trabalho em que medida dois produtos televisivos veicularam o mesmo acontecimento: a morte de Amy Winehouse. Utilizamos a classificação de Duarte (2004) e Rezende (2000) sobre gênero, subgênero e formato e encontramos pontos de diferenciação nos discursos. Notamos que tanto o Jornal Nacional quanto o Fantástico mantêm a mesma linha editorial; porém, a construção da notícia e sua apresentação varia, obedecendo características relacionadas aos formatos. Palavras-chave: morte como acontecimento; telejornalismo; formatos; elementos televisivos

\section{MUERTE DE AMY WINEHOUSE MIENTRAS ACONTECIMIENTO EN FANTÁSTICO Y EN JORNAL NACIONAL}

Resumen: Este trabajo analiza en que criterios dos productos de la televisión pasaron el mismo acontecimiento: la muerte de Amy Winehouse. Yo uso la clasificación de Duarte (2004) y Rezende (2000) sobre género, subgénero y formación y encuentro puntos de diferenciación en los discursos. Me doy cuenta que tanto Jornal Nacional o Fantástico mantienen la misma línea editorial; No obstante, la construcción de la noticia y su presentación varía, cumpliendo características relacionadas con los formatos. Palabras clave: muerte mientras acontecimiento; teleperiodismo; formatos; elementos de la televisión.

\section{THE DEATH OF AMY WINEHOUSE AS AN EVENT AT THE FANTÁTICO AND JORNAL NACIONAL}

Abstract: This paper analyzes how two diferents news broadcasted the same event: the death of Amy Winehouse. I used the classification of Duarte (2004) and Rezende (2000) on gender, subgenre and shape to find points of differentiation in the speeches. I notice that both the Jornal Nacional as the Fantástico keep the same editorial line, but the construction of the news and its presentation varies, according to characteristics related formats. Keywords: death as an event; television journalism; formats; elements television

17 Adaptado do Trabalho de Conclusão de Curso I da graduação em Jornalismo pela UFSM, sob orientação da prof. Caroline Casali. 


\section{INTRODUÇÃO}

Gaye Tuchmann (1983) define a notícia como um registro e um produto da realidade. São elas - as notícias - as responsáveis por mostrar ao público o modo de observar e interpretar uma determinada realidade. Contudo, para que um acontecimento se torne notícia, cada instância de produção midiática investe sobre ele determinadas práticas e estratégicas discursivas, o que pode produzir de um mesmo fato diferentes acontecimentos. Este trabalho traz como objetivo a análise de uma ocorrência em seu status de acontecimento: a cobertura da morte da cantora Amy Winehouse na televisão brasileira.

A artista foi encontrada morta em sua residência, na cidade de Londres, em 23 de julho de 2011. Mesmo com um histórico de envolvimento com álcool e drogas, que muitas vezes atrapalhou sua carreira, no momento posterior ao falecimento as causas de sua morte ainda eram consideradas indefinidas pela polícia que realizava a investigação. Entretanto, minutos após seu falecimento, Amy já era destaque em noticiários de todo o mundo, inclusive nos meios de comunicação do Brasil. Nesse sentido, José Rebelo (2006) explica que uma ocorrência necessita aliar sua atualidade e pregnância para virar um acontecimento: a atualidade no sentido de que a ocorrência seja de fato nova; e a pregnância na medida em que provoque uma ruptura em nosso quadro de vida por ser algo inesperado.

É fato que a morte da cantora constituiu-se em uma ocorrência que rompeu com o cotidiano - porque a morte é em si um fato inesperado, porém a maneira como a televisão brasileira trabalhou essa ocorrência enquanto acontecimento traz à tona características da produção jornalística dos acontecimentos, por vezes deixando marcas de uma narrativa pré-produzida sobre a morte - ao tom de antecipação da própria ocorrência. Diante disso, o objetivo desta pesquisa é apresentar uma análise comparativa da narrativa em questão em dois programas de grande audiência no país: o telejornal diário Jornal Nacional (JN) e a revista eletrônica Fantástico, ambos da emissora Rede Globo de Televisão. A partir da revisão dos estudos de gênero televisivo, construção do acontecimento e morte como acontecimento, buscamos identificar nos programas selecionados estratégias comunicacionais para a veiculação da morte de Amy Winehouse.

Nos próximos itens abordamos, inicialmente, conceitos de morte como acontecimento e também de gêneros, subgêneros, formatos e elementos 
A morte de Amy Winehouse como acontecimento no Fantástico e no Jornal Nacional

televisivos, propostos por Duarte (2004) e Rezende (2000). Na sequência, apresentamos de maneira mais detalhada o método de análise utilizado, bem como um breve histórico dos objetos de estudo. Em seguida, desenvolvemos a análise comparativa, na qual buscamos destacar pontos de diferenciação entre os programas, com o objetivo de compreender de que maneira os mesmos realizaram a veiculação da morte Amy Winehouse e, por fim, apresentamos as conclusões que compactam os resultados desta pesquisa.

\section{A MORTE COMO ACONTECIMENTO}

Todo o processo de produção da notícia, basicamente, necessita cumprir três etapas: que algo aconteça e modifique o estado das coisas; que um sujeito perceba essa modificação; e que o mesmo sujeito dê significação para tal mudança (CHARAUDEAU, 2006). Ainda conforme o autor, a figura humana aliada aos acontecimentos sociais é de extrema importância para que ocorra a transformação de um acontecimento em notícia e, por isso, a figura do jornalista torna-se imprescindível, já que ele insere na notícia seu julgamento pessoal, sua cultura profissional, as circunstâncias da empresa na qual trabalha, sua relação com fontes e público, e condições econômicas, sociais, políticas e históricas.

Frente a um volume tão grande de matéria-prima, é impossível não estratificar para escolher qual acontecimento é mais merecedor de participar da esfera pública como notícia. Nesse contexto, os estudos de valores-notícia propostos por Traquina (2005) formam um grupo de requisitos que, por meio da intervenção do jornalista, tendem a virar notícia mais facilmente.

Dentre os quesitos para a transformação da ocorrência em notícia, há uma tendência no jornalismo à valorização de tragédias ou fatos tristes. Nesse sentido, "a morte é um valor-notícia fundamental para essa comunidade interpretativa e uma razão que explica o negativismo do mundo jornalístico que é apresentado diariamente nas páginas do jornal ou nos écrans ${ }^{18}$ da televisão" (TRAQUINA, 2005, p. 79). Aliada a ela, a importância hierárquica do personagem noticiado, a sua visualidade frente ao mundo e a comoção que sua ausência irá gerar tendem a motivar as redações a fazer da morte e da tragédia destaques nos veículos de comunicação.

A morte de Amy Winehouse entrou no rol de acontecimentos do ano de

18 A palavra “écran", conforme o português de Portugal, tem o mesmo significado da palavra tela. 
2011, porque a mídia a trabalhou como "especial”. Ingressante no cenário musical em outubro de 2003, a cantora logo teve seu talento reconhecido devido ao seu timbre marcante e suas canções no estilo jazz escritas por ela mesma. Com o lançamento do seu segundo álbum, Back to Black, a artista britânica conquistou fãs de todo o mundo, recebendo inclusive seis indicações para o Grammy 2008. Paralelamente ao seu sucesso musical, os escândalos envolvendo bebidas e drogas faziam de Amy destaque nos noticiários mundiais. Além de realizar diversas apresentações alcoolizada, a "diva do soul”, como ficou conhecida, também foi pega portando drogas ilícitas - admitindo, então, ser viciada em maconha, cocaína e crack.

Com base nos estudos de Mouillaud (2002), que separa em categorias os tipos de mortes noticiadas pela mídia, é possível entender a razão de Amy ter seu falecimento exaltado pelos meios de comunicação. O autor relata que a morte de celebridades ou pessoas que se destacam por sua fama na sociedade ganha espaço privilegiado, pois o sentimento de perda ou comoção se intensifica quanto maior for a relação entre sobrevivente e falecido, mesmo que de maneira simbólica ou platônica. Amy, embora tenha feito uma carreira curta, foi apontada como grande revelação da música mundial e, por isso, já tinha adquirido uma legião de fãs entre anônimos e famosos que também declaravam sua admiração pela cantora. Essa relação fez dela alguém digno de um espetáculo midiático.

\section{O ACONTECIMENTO TELEVISIVO: ENTRE GÊNERO, SUBGÊNERO E FORMATO}

As narrativas televisivas em torno da morte de pessoas famosas, pelo próprio alcance da televisão enquanto meio, contribuem para a intensificação da comoção do público. A imagem audiovisual possui um papel importante na construção da opinião pública; no Brasil, por exemplo, a televisão é a mídia de maior alcance, chegando a atingir 98\% dos lares brasileiros, segundo dados do Instituto Marplan Brasil referentes ao primeiro trimestre de $2012^{19}$. A formação da cultura, bem como da opinião pública, possui uma raiz fixada no conteúdo televisivo, tendo em vista que o mesmo ultrapassa os limites da tecnologia.

Parece claro, também, que a produção televisiva sobre a morte tende

19 Dados sobre audiência televisiva estão disponíveis no site Portal Brasil, em: www. portalbrasil.net/brasil_economia.htm. Acesso em: 30 de setembro de 2012 . 
A morte de Amy Winehouse como acontecimento no Fantástico e no Jornal Nacional

a se diferenciar de acordo com o gênero da programação em questão. Os estudos de Duarte (2004) dão conta de separar o conteúdo audiovisual exibido nos canais abertos em três gêneros, sendo eles o factual (meta-realidade), o ficcional (supra-realidade) e o simulacional (para-realidade). A autora, além disso, subdivide esses gêneros em subgêneros e formatos. Conforme a pesquisadora, suas análises são baseadas não apenas na função experimental da televisão como extensão de sentidos, mas também na sua força de constituição, de geração de realidades e de caráter discursivo.

Para Duarte (2007), a meta-realidade é um tipo de realidade discursiva que possui ligação direta ao mundo exterior e natural.

Nesse tipo de realidade discursiva, a televisão fica comprometida com a veridicção - com a verdade e fidelidade aos acontecimentos noticiados, com os atores sociais envolvidos. Ela assume compromissos pautados até mesmo por legislação específica, que a obriga a buscar fontes confiáveis para o discurso veiculado, a convocar testemunhas dos acontecimentos relatados que confiram credibilidade aos relatos apresentados, pois o regime de crença que propõe é o da verdade (DUARTE, 2007, p. 3).

Ao gênero factual interessa então a meta-realidade, baseada no regime de crença da veridicção. Dentro dele, subgêneros como telejornal, documentário e reportagem constituem-se em diversificadas possibilidades, a fim de que se percebam diferentes formas de abordagem, mesmo num um único gênero. Conforme Duarte (2004), a forma de emissão específica desses subgêneros é denominada formato, e nele é que se materializam os produtos midiáticos. Seriam formatos do gênero factual, então, o Jornal Nacional, Globo Repórter, Programa do Jô, entre outros.

No gênero ficcional, o que predomina é a verossimilhança, pois trabalha com uma realidade que aparenta a verdade. Entre seus subgêneros, também segundo Duarte (2004), então inclusos a telenovela, a sitcom, a minissérie e o seriado. Os seus formatos de emissão podem ser exemplificados como Avenida Brasil, A Grande Família e Os Normais.

Por fim, ainda conforme Duarte (2004), temos também o gênero simulacional, aquele que propõe uma substituição e equivalência entre o real, o paralelo e o discurso. Nesse grupo, a exibição clara substituiu o próprio relato. Como subgêneros, a autora cita o reality show e talkshow, tendo como emissão o Big Brother e o Fama.

Em virtude do corpus de análise, este artigo foca apenas no gênero fac- 
tual, já que nele está incluso o subgênero telejornal, e o formato Jornal Nacional. Criamos ainda um novo subgênero dentro do factual, denominado revista, no qual o Fantástico torna-se formato de emissão. Essa criação será justificada a seguir, quando caracterizamos os programas analisados.

\subsection{Jornal Nacional como referência em telejornalismo}

Subgênero consolidado na televisão brasileira, o telejornal é, para Duarte (2006, p. 2), um tipo especial de noticiário já que "sua substância de conteúdo são informações sobre acontecimentos políticos, sociais, culturais, administrativos e outros, cujo âmbito pode ser local, nacional e mundial, selecionadas como relevantes para a compreensão do cotidiano". Para a autora, a seleção das informações que são veiculadas nos telejornais, além das formas de estruturação desse material, são opções estratégicas que consideram as exigências do mercado, da tecnologia e do discurso.

Atualmente, o telejornalismo conquistou uma grande parcela da grade horária das emissoras do país. Segundo o site da Rede Globo de Comunicação, um dos principais canais abertos da televisão brasileira, oito programas jornalísticos compõem sua programação diária. Desses, o JN destaca-se por estar no ar, de modo ininterrupto, há 47 anos.

Mesmo tendo sofrido inúmeras transformações desde a primeira vez que foi exibido, o maior telejornal da emissora é campeão de audiência e referência na casa de milhões de brasileiros ${ }^{20}$. Mantém uma estrutura tradicional, tendo atualmente Willian Bonner e Renata Vasconcellos como apresentadores do programa, que vai ao ar nas noites de segunda a sábado, com quase uma hora de duração. Além disso, o JN segue a risca o modelo de telejornal proposto por Rezende (2000), que veicula, por meio dos apresentadores, reportagens ao vivo ou pré-gravadas e editadas e faz entrevistas em estúdio. O seu conteúdo varia dentre os principais elementos televisivos ${ }^{21}$ como nota, notícia, reportagem, entrevista, editorial, indicador, comentár io e crônica.

20 Afirmação feita a partir dos dados disponibilizados diariamente pelo Ibope e disponíveis no site: www.ibope.com.br.

21 Rezende (2000) trabalha nota, notícia, reportagem, entrevista, editorial, indicador, comentário e crônica como formatos jornalísticos. Contudo, neste trabalho, trocou-se a definição por elementos televisivos, para facilitar a comparações com os formatos elencados por Duarte (2004). Ainda assim, as características desses elementos se mantém tais como definidas por Rezende. 
A morte de Amy Winehouse como acontecimento no Fantástico e no Jornal Nacional

\subsection{FANTÁSTICO E O GÊNERO DE REVISTA}

Inserido em uma atmosfera noticiosa e descontraída, o Fantástico surgiu em 5 de agosto de 1973 e, desde então, tornou-se um conhecido dos telespectadores brasileiros. Com duração média de duas horas e meia, o programa, que é exibido aos domingos, é um dos destaques na sua emissora. Segundo o site da Rede Globo, o Fantástico atinge, em média, 30 pontos de audiência, o que totaliza cerca de 22 milhões de telespectadores em todo o Brasil. Atualmente, Tadeu Schmidt e Poliana Abritta são os apresentadores e atuam também como repórteres, juntamente com os demais membros da equipe.

Como realização do gênero factual (da meta-realidade), o Fantástico mostra em sua programação uma mescla de reportagens, entrevistas e talkshows, tendo também a presença do jornalismo colaborativo, recurso novo na televisão, que utiliza de material enviado por espectadores para complementar a programação. Segundo López (2008), essa técnica tem sido utilizada para aperfeiçoar a produção jornalística, democratizar conteúdos e incorporar o público no processo produtivo. Lima Júnior (2009) vai um pouco mais longe e garante que o jornalismo colaborativo aproximou os produtores da audiência e permitiu que "amadores" se transformassem em criadores do conteúdo jornalístico.

Por essas diversas características listadas anteriormente, o Fantástico não consegue se enquadrar nos subgêneros apresentados por Duarte (2004). Inicialmente porque possui uma mescla de vários subgêneros, também pelo fato de ter a presença clara do jornalismo colaborativo e, por fim, apresentar quadros que se relacionam com o ficcional, tais como o "A História do Amor", que simula situações do relacionamento entre homem e mulher a partir da atuação de atores da própria emissora.

Portanto, mesmo utilizando a classificação proposta pela autora para diferenciar os dois produtos televisivos, criamos neste estudo um novo subgênero pertencente ao gênero factual, que aqui chamaremos de revista, e a sua emissão acontece por meio do formato Fantástico. A escolha do nome se deu em virtude do próprio discurso do programa, que, na voz de seus apresentadores, se intitula como "revista eletrônica".

Conforme dito anteriormente, alguns elementos do semanário remetem ao conteúdo ficcional, mesmo assim ele será enquadrado ao grupo factual, já que, em sua maioria, esses quadros não prejudicam duas de suas princi- 
pais características: relação de correspondência direta entre real e discurso, e compromisso com a veracidade e fidelidade do relato.

\section{METODOLOGIA}

Analisamos, nesta pesquisa, em que medida dois formatos televisivos, pertencentes ao gênero factual, veicularam um mesmo acontecimento jornalístico. Com isso, acreditamos ser possível perceber ainda se a linha editorial da Rede Globo se mantém na veiculação da morte da cantora Amy Winehouse ou se cada produto, em suas particularidades, possui uma autonomia para apresentar a informação.

Temos como corpus de análise o Fantástico e o JN, estando os dois programas entre os principais da grade atual da Rede Globo. Em resumo, o Fantástico vai ao ar semanalmente e, com a presença de dois apresentadores, exibe diversos quadros, tanto de caráter noticioso como ficcional. Já o JN é exibido de segunda-feira a sábado e mantém características do telejornal tradicional, como dois apresentadores na bancada ${ }^{22}$ chamando notícias, reportagens e outros elementos televisivos.

Utilizamos para a análise todo o conteúdo veiculado sobre Amy Winehouse no programa Fantástico exibido no domingo, 24 de julho de 2011, um dia após a morte da cantora. Acerca do JN, foram analisados os programas veiculados na semana de 23 a 29 de julho de 2011, também no que tange ao conteúdo sobre a morte de Amy. Ao todo, o corpus desta pesquisa se constitui em, aproximadamente, 24 minutos de programação do Fantástico e 29 minutos de $\mathrm{JN}$.

Utilizamos como método de pesquisa a análise de conteúdo (AC), proposta por Gaskell e Bauer (2002), pois acreditamos que, com ela, seja possível identificar valores a partir dos quais o jornalismo constitui a morte de Amy Winehouse como acontecimento. Contudo, vale lembrar que a AC é geralmente voltada para análise de textos verbais, por isso buscamos nos deter nos estudos de Diane Rose (2002), que desenvolveu uma técnica para a utilização da $A C$ no que se refere a imagens em movimento. A autora, ao realizar uma pesquisa sobre a representação da loucura na televisão britâni-

22 A partir de 2015 o JN alterou sua forma de apresentação das notícias e os apresentadores também passaram a circular pelo estúdio. Porém, na época da veiculação do acontecimento em análise o modelo de apresentação mantinha-se com os mesmos sentados na bancada. 
A morte de Amy Winehouse como acontecimento no Fantástico e no Jornal Nacional

ca, criou técnicas de codificação para elementos audiovisuais.

Finalizando os recursos metodológicos, consideramos a categorização de Lage (2001) para as fontes noticiosas - aquelas utilizadas para dar credibilidade à informação. A classificação de fontes proposta pelo autor as divide em grupos e categorias. No grupo "a”, ele insere as fontes “oficiais" (instituições que preservam algum poder de Estado); "oficiosas" (as não autorizadas a falar em nome de uma organização ou personalidade); e "independentes" (organizações não governamentais). No grupo "b”, por sua vez, são aprontadas as fontes "primárias" e "secundárias" na perspectiva da sua relação direta e indireta com os fatos, respectivamente. E, por último, no grupo "c" o autor indica as "testemunhas", que presenciam os fatos e os "experts", especialistas em determinados assuntos e que interpretam os eventos. Com base nessa categorização, também contabilizamos em que medida os programas se preocuparam com a veracidade do acontecimento.

\section{RESULTADOS ENCONTRADOS: O NOVO FORMADO ANCORADO NO TRADICIONAL}

Tanto o Fantástico quanto o JN possuem uma característica semelhante, aquela de veicular assuntos nacionais e internacionais em sua programação. Contudo, o JN trabalha de maneira factual, privilegiando a notícia em si e não a transformando em história dramatizada. Já o Fantástico utiliza recursos adicionais, que enriquecem a sua programação e alia informação com entretenimento, dramatizando o conteúdo veiculado.

Neste item, descrevemos os dados obtidos a partir da observação dos programas analisados, identificando a frequência com que Amy Winehouse aparece nos produtos a partir da porcentagem de suas citações em comparação com o restante das pautas abordadas em cada programa.

A cantora Amy Winehouse teve seu falecimento anunciado ao meio dia do sábado, 23 de julho, e o JN foi ao ar aproximadamente oito horas mais tarde e, até a sexta-feira, 29, dedicou 16,06\% de sua programação ao assunto. Já o Fantástico, no domingo posterior à morte da artista, e em um programa intitulado especial, conforme discurso dos apresentadores, utilizou-se de 21,18\% de sua programação para tratar de Amy Winehouse.

Ao comparar numericamente os dois programas televisivos percebemos que a diferença entre ambos na veiculação da morte de Amy Winehouse é pequena. Entretanto, devido ao corpus correspondente ao JN ser maior, 
identificamos que o mesmo tratou a ocorrência de maneira factual, privilegiando o momento em que o acontecimento se constitui, deixando-o de lado no decorrer da semana.

O maior tempo de abordagem da morte de Amy no JN foi conferido durante o sábado de seu falecimento. O que notamos ao quantificar o espaço conferido à cantora no telejornal é que Amy esteve em evidência apenas no dia de seu falecimento (sábado); já na segunda e terça-feira, somente uma reportagem e uma matéria fizeram parte da grade de programação do telejornal.

Ambos os formatos televisivos utilizaram de elementos variados para noticiar o falecimento de Amy Winehouse. A reportagem, contudo, destacou-se na programação do Fantástico e do JN, isso porque sua duração é maior, permitindo contar uma história que envolva personagens e prenda a atenção do telespectador. Para Jean-Jacques Jespers (1998), uma reportagem pode sensibilizar o público, chamar a sua atenção para uma questão e mobilizá-lo. Foi o que aconteceu no caso da cantora Amy Winehouse, além de simplesmente noticiarem o acontecimento, ambos os formatos pretendiam gerar uma comoção no seu público, tendo em vista que sua morte alcançou dimensões mundiais.

Dentre os diversos elementos presentes, vale ressaltar que o JN também inseriu, significativamente, o comentário (cerca 16\% da programação), que foge da informação e mostra o posicionamento do programa, trazendo para o estúdio um especialista no assunto, que muitas vezes é reconhecido pelo público e transmite credibilidade ao dar sua opinião pessoal sobre determinado assunto. Para Rezende, o comentário é a "matéria jornalística em que um jornalista especializado em um determinado assunto (...) faz uma análise, uma interpretação de fatos do cotidiano" (REZENDE, 2000, p. 158159).

Nesse sentido, o comentário feito por Nelson Motta, um especialista em música, apareceu em três momentos do telejornal exibido no sábado, totalizando 5'30" de espaço conferido ao elemento. É importante destacar, porém, que o tempo em que ele se fez presente foi dividido, inserindo-o no meio de outros elementos que visavam a pauta Amy Winehouse. Nessas alterações em que o JN ora apresentou uma informação nova, ora comentou sobre o acontecido, foi possível identificar tons de formalidade e informalidade, conferindo descontração à narrativa do produto. Essa afirmação pode ser exemplificada no momento em que o apresentador do telejornal ques- 
A morte de Amy Winehouse como acontecimento no Fantástico e no Jornal Nacional

tionou o comentarista: "não era surpresa que Amy Winehouse ameaçava a carreira dela com álcool e drogas, mas a vida também?”, o mesmo após um sorriso e um gesto de confirmação respondeu: "olha, ela era uma crônica de uma morte anunciada, mas os fãs estão sempre esperando um milagre". O "milagre" relatado pelo comentarista é apresentado de forma irônica, já que no discurso do especialista ele seria impossível tendo em vista o comportamento que Amy apresentava ao público.

Diferente do JN, o Fantástico fez uso de elementos não utilizados no telejornalismo tradicional. Um exemplo de tal afirmação é que grande parte do acontecimento abordado foi apresentado por meio de "homenagens" (cerca de $20 \%$ da programação), termo este designado pelo próprio produto e anexado à classificação de elementos. O programa exibiu quadros em que apresentava celebridades e fãs caracterizados com figurinos que lembravam Amy Winehouse e cantando sucessos da artista, aproximando-se de um quadro de variedades e do ficcional, devido às caracterizações.

A formatação do subgênero revista é muito parecida com a dos programas factuais apresentados por Duarte (2004), porém, ao mesclar vários subgêneros e apresentar quadros ficcionais a informação torna-se espetáculo, virando uma espécie de show de informações. Essa alternativa faz o público que assiste ao programa ter a sensação de estar bem informado, porém de uma maneira atrativa, divertida e que utiliza recursos não explorados nos outros subgêneros da meta-realidade, como por exemplo, o telejornal.

Outro destaque no que se refere aos elementos utilizados pelo Fantástico e JN é a utilização do "ao vivo" por ambos os produtos. Esta designação também se estabelece aqui como elemento, complementando a classificação de Rezende (2000), por conta das necessidades do corpus de análise. Sua diferenciação está no fato de que nele é possível perceber a presença do repórter no local onde a notícia está acontecendo.

Para York (1998) o "ao vivo" é utilizado devido a algumas razões intencionais, como oferecer uma comunicação direta entre emissor e receptor, aumentar a credibilidade da informação - já que ela é comprovada por ocorrer no local - e, ainda, possuir um baixo custo de produção. Ao comparar os produtos, notamos que o JN utilizou aproximadamente três vezes mais o formato do que o outro programa. Essa constatação pode ser entendida tendo em vista que o telejornal teve menos tempo para ser produzido e também devido ao que já foi constatado anteriormente, no que diz respeito à factualidade no telejornalismo. Já o Fantástico pode utilizar outros re- 
cursos para a veiculação da morte da cantora, sendo menos informativo e espetacularizando o acontecimento, indo ao encontro do que propomos ao criar o subgênero revista.

Dando complemento a análise e buscando resultados ainda mais significativos, utilizamos os conceitos de Lage (2001), no que tange a utilização de fontes noticiosas. Fica evidente que os dois programas fizeram uso de um extenso quadro de fontes para a veiculação de seus elementos televisivos e, ao analisar o material coletado, percebemos que as fontes possuem um papel importante dentro da construção da notícia, seja ela no Fantástico ou JN. Essa afirmação se comprova quando destacamos o que diz Traquina (2005), se referindo as fontes como o ponto de partida do texto jornalístico. $\mathrm{O}$ autor afirma ainda que elas - as fontes - podem ser qualquer pessoa envolvida, conhecedora ou que sirva de testemunho para um determinado acontecimento. Através da maneira como são escaladas, o conteúdo jornalístico ganha sentido e forma.

Para que fosse possível uma análise que seguisse os parâmetros propostos por Lage (2001), contabilizamos o número de vezes em que cada produto utilizou de tal fonte. Dessa forma, afirmamos que o JN fez uso - em quantidade - de mais fontes que o Fantástico (125 para 84 vezes). Essa afirmação pode ser justificada devido aos próprios parâmetros de telejornalismo, que indicam tempo máximo disponibilizado para cada fonte. Além disso, o Fantástico, por utilizar outros elementos que não os habituais de telejornalismo, pode exibir quadros mais longos - em duração - como a veiculação de clipes de músicas de Amy Winehouse, o que pode ter diminuído o número de fontes utilizadas.

Conforme Lage (2001) das três fontes pertencentes ao grupo "a", as oficiais são tidas como as mais confiáveis. Nesse sentido é possível dizer que o JN se preocupou muito mais com sua credibilidade, já que mostrou 15 fontes enquanto o Fantástico apenas três. No que se refere às oficiosas, os números se mantiveram iguais (12). Referente às fontes independentes, novamente o telejornal mostrou utilizar mais vezes que a revista (22 para 14).

Quanto ao grupo "b", aquele que separa em fontes primárias e secundárias, o número de fontes utilizadas pelo JN para construir a programação mais do que triplicou em relação ao Fantástico no que se refere as secundárias (38 para 10). Conforme o autor, "fontes secundárias são consultadas para a preparação de uma pauta ou a construção das premissas genéricas ou contextos ambientais" (LAGE, 2001, p. 66). Portanto, pelo fato de o JN 
A morte de Amy Winehouse como acontecimento no Fantástico e no Jornal Nacional

ter ido ao ar um dia antes do Fantástico, o mesmo precisou buscar mais informações. O Fantástico por sua vez, pode se ancorar no telejornal, não sendo necessária a utilização de fontes que construíssem a pauta, já que ela já havia sido construída por outro formato da emissora.

Por fim, outro número significativo no que se refere à contagem das fontes se deu na utilização de testemunhas, pertencentes ao grupo " $c$ ". Dessa vez, o Fantástico ultrapassou o JN (25 para 17 vezes). A explicação fica evidente se levarmos em consideração que esse tipo de fonte é normalmente movida pela emoção. O Fantástico, por construir uma narrativa para a morte da cantora, utilizou-se muito mais de recursos que contam uma história e não apenas noticiam o acontecimento.

Como último recurso para a análise comparativa dos formatos, e com base em Diana Rose (2002), codificamos, também, todo o conteúdo relacionado à morte da cantora no Fantástico e JN. Mensuramos a frequência em que o sujeito Amy Winehouse era substituído por outros adjetivos, o cenário em que a artista aparecia no momento em que ilustrava os elementos apresentados e também a ação que ela realizava no momento em que aparecia na programação de ambos os produtos.

Percebemos que ambos os programas substituíram o nome de Amy Winehouse por adjetivos que lembravam sua carreira profissional. Termos como "cantora", "artista", "talentosa" foram lembrados pelos formatos analisados. Contudo, é possível perceber que o JN apresentou mais informações como um dado novo no que se refere aos sujeitos, totalizando 65, já o Fantástico se preocupou em substituir o nome de Amy por termos que a caracterizassem em 56 vezes. Percebemos então que o telejornal utilizou-se dos sujeitos na intenção de informar, palavras como "letrista", "intérprete" e "premiada", no contexto do discurso, apresentaram nova informação sobre o acontecimento noticiado.

No que se refere aos cenários mostrados por ambos os formatos televisivos, ou seja, os locais em que Amy Winehouse apareceu no momento em que é citada pelos programas, é perceptível que o telejornal utilizou fotografias de jornais para ilustrar aquilo que falou. Ao mostrar reportagens veiculadas em outros meios de comunicação, o veículo comprovou que, em um diferente momento da história, outro meio já noticiou e comprovou aquilo, com isso o JN passou segurança ao afirmar, por exemplo, que "a música estava em luto", ou que seus fãs "estavam inconformados com a perda", e também se eximiu da responsabilidade da informação. 
Ainda falando de cenários, o Fantástico utilizou, em um número significativo se comparado ao JN, imagens de apresentações de Amy Winehouse em vídeos filmados por pessoas que estavam no local. Novamente ele buscou provar que não foi penas o programa que percebeu que algumas atitudes da cantora foram responsáveis pelo fim de sua vida, já que a informação foi produzida por fãs e apenas reproduzida pelo programa, indo ao encontro do que propõe o jornalismo colaborativo.

É interessante ressaltar também que o Fantástico conseguiu ir ainda mais longe na utilização de vídeos feitos por produtores externos. Por diversos momentos em que afirmou que "as drogas foram responsáveis pela ascensão e queda de uma deusa" ele mostrou cenários caseiros, disponibilizados pela cantora em filmagens próprias. Amy Winehouse apareceu usando drogas, e com isso quem estava comprovando o fato não era nenhum espectador, mas sim a própria personagem envolvida no assunto, o que intensificou ainda mais a dramatização do acontecimento.

De maneira geral, é através dos cenários que percebemos grandes diferenciações entre os dois formatos. Apesar do JN também utilizar pequenas parcelas de vídeos feitos por fãs, esse material fica em evidência apenas no Fantástico, que se diferencia do telejornal. Em contrapartida o JN evidencia a informação de outros produtos jornalísticos, através das imagens de jornais, o que lhe oferece uma credibilidade maior.

Por fim temos a quantificação das ações envolvendo Amy Winehouse. Estas também podem ser vistas como adjetivação, porém, diferente dos sujeitos, elas atribuem a responsabilidade do que é dito à própria personagem que havia falecido. As ações nada mais são do que um subsídio de adjetivação implícito pelos dois formatos televisivos.

Quanto a este item tanto o Fantástico quanto o JN mantiveram uma característica semelhante: adjetivar Amy Winehouse, atribuindo-Ihe características que envolveram sua postura pessoal, como o abuso do álcool e das drogas, fator que poderia ter levado ao seu falecimento. O JN, mesmo afirmando que as circunstâncias da morte da cantora ainda não haviam sido esclarecidas, mostrou imagens de Amy caindo nos palcos alcoolizada e fotografias de sua decadência física em virtude das drogas. O Fantástico, sob a mesma visão, mostrou, além de imagens da cantora bêbada e fotografias de decadência, um vídeo de Amy usando drogas, que havia sido disponibilizado na internet.

Em uma de suas reportagens, o programa do subgênero revista apre- 
A morte de Amy Winehouse como acontecimento no Fantástico e no Jornal Nacional

sentou ações da cantora que desagradam grande parte de espectadores e, na sequência, relacionou-as com outros ídolos que morreram com a mesma idade de Amy, vinte e sete anos ${ }^{23}$.

No único momento em que o semanário apresentou um expert para falar sobre o assunto, o mesmo não falou, diretamente, sobre Amy Winehouse. Contudo, enquanto divagou sobre as consequências das drogas e da bebida no corpo humano, imagens da artista cobriram a fala do entrevistado. Por ora ficou evidente, então, que ambos os formatos utilizaram-se da descrição de ações para antecipar os resultados da autópsia, que ainda não tinham sido divulgados, atribuindo a causa da morte de Amy às drogas. Os posicionamentos dos programas, que neste caso foram iguais, não foi construído via discurso verbal, mas sim através de imagens, que sublinarmente, complementavam o que o discurso dos apresentadores, repórteres e entrevistados dizia.

\section{CONCLUSÃO}

Ao analisar a cobertura da morte de Amy Winehouse pelo Fantástico e pelo JN, percebemos que ambos valorizaram a tragédia e o fato triste, mantendo uma mesma linha editorial no que tange à escolha da morte como acontecimento digno de se transformar em notícia. Vale ressaltar, ainda, que o subgênero revista se apoiou no telejornal, contudo, buscou alterar elementos de exibição da informação a fim de que o conteúdo não se tornasse repetitivo.

Enquanto o JN manteve elementos base, preocupando-se com a credibilidade da informação e a factualidade do conteúdo, o Fantástico fez desse acontecimento uma história com enredo, que, além de noticiar, também dramatizou, buscando entreter o telespectador. A utilização de recursos adicionais, como o quadro "homenagens", comprova tal constatação. Aliado a isso, a evidência do jornalismo colaborativo faz com que se perceba que o subgênero revista rompe com o jornalismo tradicional na televisão, dando espaço para novas formas de coletar informação.

Em contrapartida o JN baseou-se em fontes oficiais, não cedendo es-

23 Tendo por base a morte de diversos artistas aos 27 anos de idade, a mídia em geral criou o "Clube dos 27", termo designado para tratar de uma Teoria da Conspiração que levou famosos (Robert Johnson, Brian Jones, Jimi Hendrix, Janis Joplin, Jim Morrison e Kurt Cobain) a morreram com essa idade, assim como Amy Winehouse. 
paço para "vídeos amadores". Tendo necessidade de buscar informação, o telejornal priorizou a exibição de imagens de outros veículos de comunicação, como jornais impressos, e com isso se eximiu da responsabilidade pelo dito.

Fica evidente ainda que os dois formatos pretendiam gerar comoção em seu público, com a intenção de despertar o sentimento de perda, inclusive naqueles que não eram fãs da artista. O Fantástico, principalmente, o que comprova ao trazer um número significativo de testemunhas, que explanavam sobre a perda física e simbólica de Amy Winehouse, além de reviver a sua história.

Por fim, concluímos afirmando que a morte como um valor-notícia e sua venda como acontecimento são evidentes na Rede Globo, mas sua forma de abordagem varia conforme o formato em que a morte é exibida. Ao tom de antecipação dessa morte, a emissora mostrou, através de imagens de Amy, possíveis causas para o falecimento. Essas imagens mexem com a opinião do telespectador, criando uma verdade que parece inquestionável, mas cuja autoria se dilui devido às várias estratégias discursivas utilizadas pelos formatos em questão.

\section{REFERÊNCIAS}

BAUER, M. Análise de conteúdo clássica: uma revisão. In: M.Bauer e G.Gaskell (Ogs.). Pesquisa qualitativa com texto, imagem e som. Petrópolis: Vozes, p. 189-217.

CHARAUDEAU, P. Discurso das Mídias. São Paulo: Contexto, 2006.

DUARTE, E. B. Televisão: ensaios metodológicos. Porto Alegre: Sulina, 2004. Col. Estudos sobre $\mathrm{o}$ audiovisual

. Televisão: entre gêneros, formatos e tons. Anais do XXX Encontro dos Núcleos de Pesquisa em Comunicação - XXX NP, Universidade Católica de Santos, Santos, 2007.

. Produção televisual: incidências do tempo sobre o tom. UNIrevista - Vol. 1, $n^{\circ}$ 3:3 (julho 2006) ISSN 1806, 2006.

LAGE, N. A reportagem: teoria e técnica de entrevista e pesquisa jornalística. Rio de Janeiro: Record, 2001.

LIMA JÚNIOR, W. T. Mídia Social Conectada: produção colaborativa de informação de revelância social em ambiente tecnológico digital. Anais do VII Encontro Nacional de Pesquisadores em Jornalismo - SBPJor, USP, São Paulo, 2009.

LÓPEZ, X. La participación em los diários digitales: similitudes y diferencias entre los cibermedios europeos y brasileños. Anais do VI Encontro Nacional de Pesquisadores em 
A morte de Amy Winehouse como acontecimento no Fantástico e no Jornal Nacional

Jornalismo - SBPJor, UMESP, São Bernardo do Campo, 2008.

MOUILLAUD, M. As grandes mortes na mídia. In: MOUILLAUD. M (Org.). O Jornal: da forma ao sentido. Brasília: Paralelo 15, p. 349-361.

REBELO, J. Prolegómenos à narativa mediática do acontecimento. In: Trajectos - Revista de Comunicação, Cultura e Educação. Lisboa, no 8-9, 2006, p. 17-27.

REZENDE, G. J. Telejornalismo no Brasil: um perfil editorial. 2 ed. São Paulo: Summus, 2000.

ROSE, D. Análise de imagens em movimento. In: M. BAUER; G. GASKELL (Orgs.). Pesquisa qualitativa com texto, imagem e som: um manual prático. Petrópolis: Vozes, p. 343364.

TUCHMAN, G. La producción de la noticia: estudio sobre la construcción de la realidad. Barcelona: Gustavo Gilli, 1983.

TRAQUINA, Nelson. Teorias do jornalismo. A tribo jornalística - uma comunidade interpretativa transnacional. Florianópolis: Insular, 2005.

YORKE, I. Jornalismo diante das câmeras. São Paulo: Summus, 1998. 


\section{Luiz Fernando Greiner Barp}

Graduado em Comunicação Social - Hab. Jornalismo pela Universidade Federal de Santa Maria (UFSM) e especialista em Cinema e Realização Audiovisual pela Universidade Comunitária da Região de Chapecó (Unochapecó).

RECEBIDO EM: 21/05/2013

APROVADO PARA PUBLICAÇÃO: 06/10/2015 